\title{
Inovasi Startup Business Kuliner Berbasis Budaya dalam Rangka Peningkatan Kesejahteraan Masyarakat Desa Wisata Peniwen, Kecamatan Kromengan, Malang, Jawa Timur.
}

\author{
Hendra S.E, M.M1*, Verina Wijaya S.E, M.Sc², Clarissa Susilo S.E3 , M.M, Rizki Adityaji S.E4, M.Par5, \\ Monique Dwijayanti S.E6, M.M, Christy Widyati S.E7, M.Sc, Erris Kusumawijaya S.E ${ }^{8}$ \\ 1,2,3dst Universitas Ciputra \\ * Penulis Korespondensi: E-mail: hugo_smart@yahoo.com
}

\begin{abstract}
Tourism is one of the priority sectors of development development both at the local and central government level. As one of the educational institutions engaged in the development of regional tourism potential, it is very important that there is cooperation between local governments and private parties. Peniwen village is one of the tourist villages in Malang that is in demand by east Java people who want to feel the atmosphere of a traditional village. With this background, we carry out obligations in the form of community service activities in tourist destinations in the form of local culinary availability resulting from the exploration of local culture that empowers the potential of natural products and cultural culture of people's daily lives. Providing education about the concept of community-based tourism development is the first step to changing people's mindset about tourism. To support these educational and empowerment activities, it is also necessary to touch the process of implementing business start-ups, ranging from design, packaging, and promotion. The results of this community service are the results of research published in national proceedings/journals, increased knowledge, skills and income of local people, the creation of documentary videos and national mass media coverage.
\end{abstract}

Keywords: Culinary Business Startup, Innovation, tourist village

\begin{abstract}
Abstrak
Pariwisata merupakan salah satu sektor prioritas pengembangan pembangunan baik di tingkat pemerintah daerah maupun pusat. Sebagai salah satu instansi pendidikan yang bergerak di bidang pengembangan potensi wisata daerah, sangat penting adanya kerjasama antara pemerintah daerah dan pihak swasta. Desa Peniwen adalah salah satu dari desa wisata yang ada di malang yang diminati oleh masyarakat Jawa Timur yang ingin merasakan suasana desa tradisional. Dengan latar belakang tersebut maka kami maelaksanakan kewajiban berupa Kegiatan pengabdian masyarakat di daerah tujuan wisata berupa ketersediaan kuliner lokal hasil dari eksplorasi budaya setempat yang memberdayakan potensi hasil alam dan kultur budaya kehidupan sehari hari masyarakat. Memberikan edukasi tentang konsep pengembangan wisata berbasis masyarakat menjadi langkah awal untuk mengubah mindset masyarakat tentang pariwisata.Untuk mendukung kegiatan edukasi dan pemberdayaan tersebut maka diperlukan juga sentuhan proses penerapan start up bisnis, mulai dari desain, pengemasan, dan promosi. Luaran dari hasil pengabdian masyarakat ini berupa hasil penelitian yang dipublikasikan dalam prosiding/jurnal nasional, peningkatan pengetahuan, keterampilan dan pendapatan masyarakat lokal, pembuatan video dokumentasi serta pemberitaan media massa nasional.
\end{abstract}

Kata kunci: Startup Business Kuliner, Inovasi, Desa Wisata 


\section{PENDAHULUAN}

Desa Peniwen, yang merupakan salah satu Desa wisata di wilayah Kecamatan Kromengan. Kabupaten Kepanjen, Malang , Jawa Timur. Berada disebelah barat kota kepanjen , kurang lebih dapat ditempuh selama 30 menit dari kota Kepanjen. Desa ini memiliki keindahan alam yang bagus dan memiliki potensi sebagai wisata edu tourism dimana masyarakat yang berkunjung ke desa wisata Peniwen bisa menikamati keindahan alam sambil belajar kehidupan masyarakat lokal. Fasilitas pendukung didalam pelengkap wisata berupa ketersediaan akomodasi belum maksimal dan ketersediaan makanan yang ada kurang mencerminkan budaya lokal yang ada Konsep pengembangan wisata kuliner berbasis budaya merupakan sebuah gagasan untuk meningkatkan kesejahteraan masyarakat lokal melalui bisnis makanan yang bercitarasa lokal yang mengacu pada sejarah kuliner

Selama ini, desa wisata Peniwen hanya menyediakan kuliner yang berasal dari menu sehari hari tanpa melihat nilai bisnis dan sejarah yang mungkin bisa dikembangkan .Untuk itu, perhatian utama dari kegiatan pengabdian masyarakat yang akan dilaksanakan di desa ini adalah berupaya mengangkat nilai kuliner peniwen dari sisi bisnis dan sejarah agar mampu meningkatkan nilai komoditi pariwisata di tingkat internasional yang nantinya diharapkan mampu meningkatkan kondisi ekonomi masyarakat lokal yang berkontribusi secara aktif dalam proses pengembangan pariwisata di Indonesia.

Kehidupan sosial ekonomi masyarakat Desa Peniwen rata-rata masih rendah. Masyarakat lokal sendiri belum memiliki mindset yang baik tentang pariwisata, sehingga mereka tidak menyadari bahwa desa mereka sebetulnya bisa dikembangkan menjadi destinasi wisata yang layak untuk dikunjungi oleh wisatawan domestik maupun asing. Seharusnya masyarakat lokal bisa berperan sebagai salah satu stakeholder dalam pengembangan wisata di kawasan ini. Dengan demikian, masyarakat tidak harus selalu menggantungkan hidupnya dari mata pencaharian berkebun yang hasilnya juga tidak signifikan bagi peningkatan kesejahteraan hidup mereka.

Selama ini, desa wisata Peniwen hanya menyediakan kuliner yang berasal dari menu sehari hari tanpa melihat nilai bisnis dan sejarah yang mungkin bisa dikembangkan .Untuk itu, perhatian utama dari kegiatan pengabdian masyarakat yang akan dilaksanakan di desa ini adalah berupaya mengangkat nilai kuliner peniwen dari sisi bisnis dan sejarah agar mampu meningkatkan nilai komoditi pariwisata di tingkat internasional yang nantinya diharapkan mampu meningkatkan kondisi ekonomi masyarakat lokal yang berkontribusi secara aktif dalam proses pengembangan pariwisata di Indonesia.

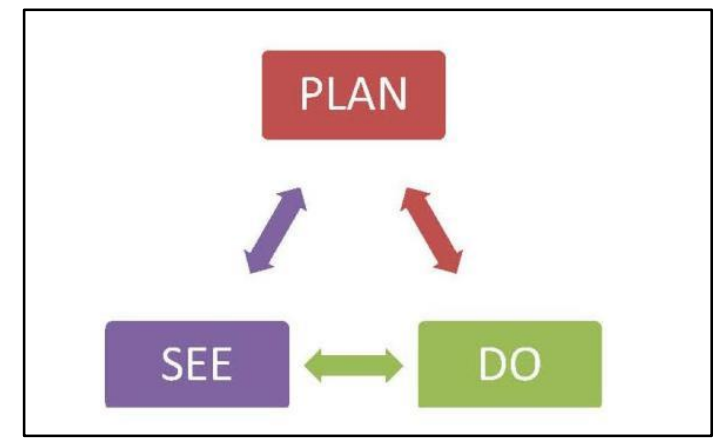

Gambar 1. Pola Implementasi Lesson Study dalam Pengembangan Kompetensi Masyarakat Desa Peniwen

(Sumber : Suratno, 2010) 


\section{METODE PELAKSANAAN}

Dalam melakukan perencanaan dan pelaksanaan pelatihan kuliner berbasis budaya sesuai dengan solusi yang direncanakan, tim akan melakukan beberapa tahapan atau langkah sebagai berikut:

1. Mengumpulkan data literatur yang berupa data statistik, publikasi dan pemberitaan tentang kuliner majapahit.

2. Kegiatan observasi, survey di lapangan dengan tujuan membuat peta potensi bisnis wisata kuliner berbasis budaya. Kegiatan observasi dilakukan selama 2 bulan bekerja sama dengan tokoh masyarakat di Dewa Peniwen, dalam hal ini Kepala Desa dan para perangkat desa.

3. Workshop pelatihan kuliner berbasis budaya terhadap ibu ibu PKK desa peniwen.

4. Mengatur jadwal dan agenda kegiatan pelatihan bisnis kuliner berbasis budaya untuk memberdayakan masyarakat dengan melibatkan para ahli dan praktisi di dalam bidang pengembangan pariwisata berbasis masyarakat, pembangunan bisnis wisata berbasis masyarakat, pengembangan SDM masyarakat lokal dan pembuatan produk kuliner.

5. Membuat platform online untuk memasarkan produk kuliner dari Desa Peniwen dan memberian pelatihan dalam penggunaan sosial media untuk kepentingan promosi wisata Desa Peniwen .

\section{HASIL dan PEMBAHASAN}

Dalam kegiatan pengabdian masyarakat ini, proses pengembangan IPTEK (Ilmu Pengetahuan dan Teknologi) dilakukan dalam proses sebagai berikut:

1. Pelatihan penggunaan internet dan sosial media, seperti instragram, facebook, dan lain-lain untuk sarana mempromosikan kuliner local berbasis budaya.

2. Pelatihan dasar dan teknik desain materi promosi kepada masyarakat supaya bisa membuat materi promosi yang berkualita baik.

Gambar literatur budaya kuliner Majapahit, yang bisa diakulturasikan dengan budaya kuliner setempat.

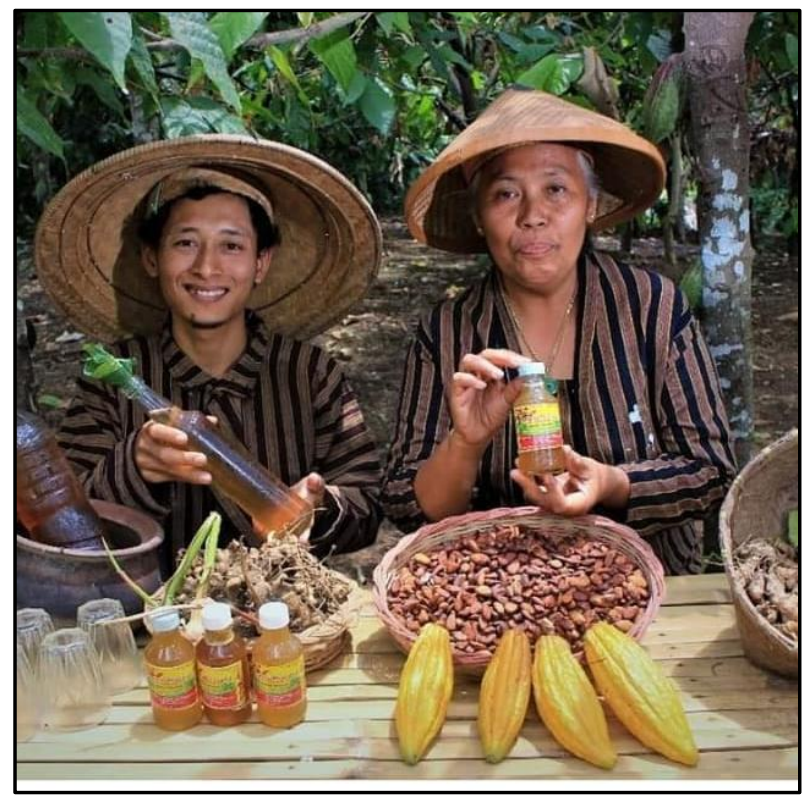

Gambar 2. Foto Kegiatan 1 


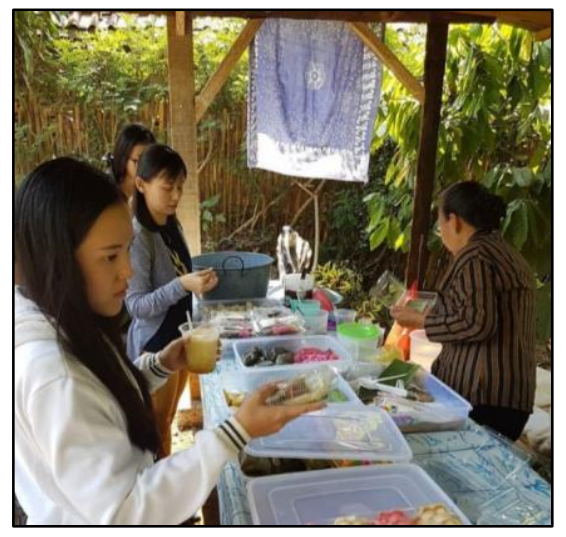

Gambar 3. Foto Kegiatan 2

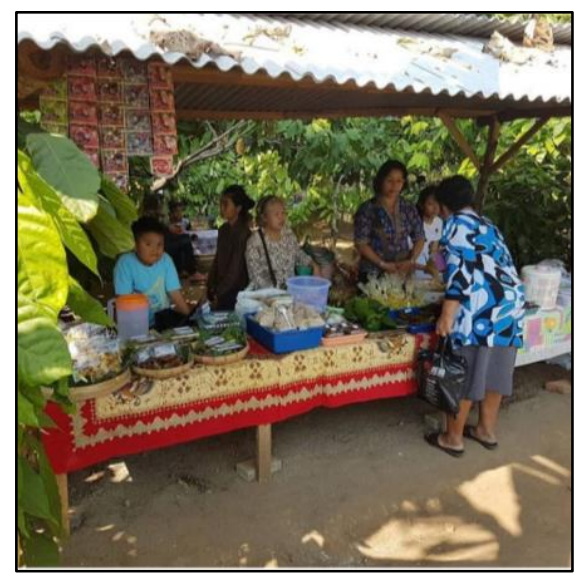

Gambar 4. Foto Kegiatan 3

Inovasi Start Up Business Kuliner berbasis budaya Desa wisata Peniwen.

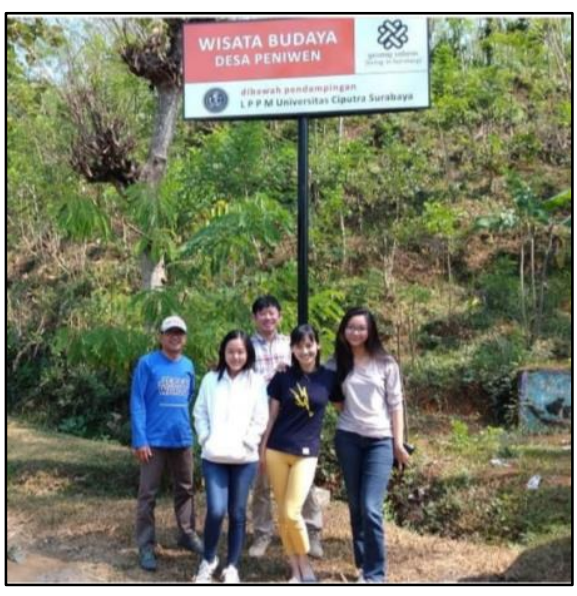

Gambar 5. Foto Kegiatan 4 


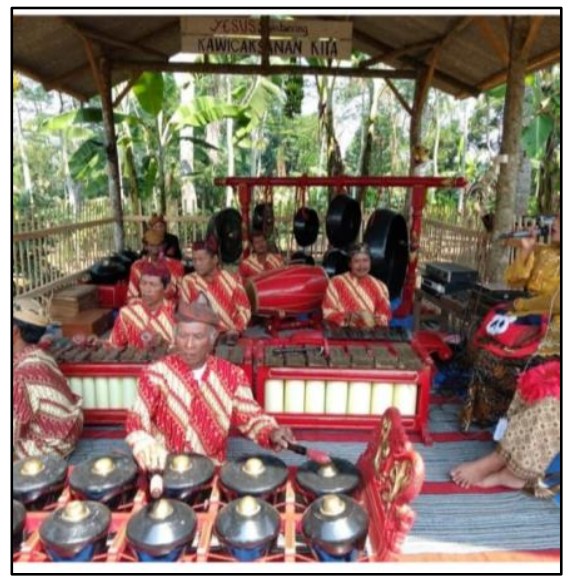

Gambar 6. Foto Kegiatan 5

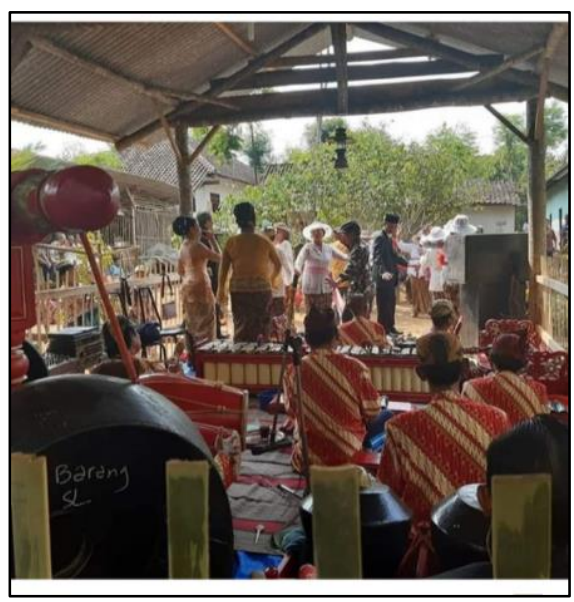

Gambar 7. Foto Kegiatan 6

Untuk meningkatkan kualitas kuliner desa wisata Peniwen yang berbasis nilai sejarah maka perlu dilakukan sebuah kegiatan yang terencana, terstruktur dan komprehensif dengan menggunakan pendekatan edukasi dan pemberdayaan. Hal ini bertujuan untuk memberdayakan masyarakat lokal supaya bisa menjadi subyek pengembangan destinasi wisata dan mendapatkan dampak yang positif baik secara sosial dan ekonomi. Hal ini bisa dicapai dengan melakukan pendampingan dan pelatihan dengan beberapa langkah berikut:

1. Workshop Kuliner berbasis budaya.

2. Membangun usaha berbasis masyarakat untuk melayani kebutuhan wisatawan seperti:Pendampingan dalam pembuatan produk khas sebagai oleh-oleh wisatawan.

3. Mendampingi masyarakat lokal dalam mempergunakan teknologi dalam memasarkan kuliner berbasis budaya. Hal ini dilakukan dengan proses:

a. Pelatihan tentang internet.

b. Pelatihan tentang marketing online / digital marketing untuk memanfaatkan sosial media sebagai sarana promosi produk dan jasa untuk wisatawan. 


\section{KESIMPULAN}

Dari kegiatan pengabdian kepada masyarakat yang telah kami lakukan maka dapat ditarik kesimpulan bahwa dengan melakukan pendampingan dan pelatihan secara terstruktur melalui edukasi dilakukan dengan cara memberikan seminar/pelatihan tentang literaturbudaya, khususnya literatur budaya kuliner Majapahit, yang bisa diakulturasikan dengan budaya kuliner setempat sehingga dapat mengangkat nilai kuliner peniwen dari sisi bisnis dan sejarah agar mampu meningkatkan nilai komoditi pariwisata di tingkat internasional yang nantinya diharapkan mampu meningkatkan kondisi ekonomi masyarakat lokal yang berkontribusi secara aktif dalam proses pengembangan pariwisata di Indonesia.

\section{DAFTAR PUSTAKA}

Wibowo , AS (1979). Prasasti alas santan tahun 861 saka Muljana, S (1979). Srivijaya's teritirial expansion in the seventh and eight centuries Mambo, W dan Nurhayati, H (1992). Makanan dan pakaian pada masa Majapahit 